\title{
Ensinar metodologia: questões epistemológicas nas proposições de 33 programas de ensino da disciplina em cursos de jornalismo
}

\section{Luís Mauro Sá Martino}

Professor do mestrado em comunicação da Faculdade Cásper Líbero. Doutor em ciências sociais pela Pontifícia Universidade Católica de São Paulo (PUC-SP).

E-mail: Imsamartino@gmail.com

Rafael Grohmann

Professor e coordenador do mestrado profissional em jornalismo do Fiam-Faam - Centro Universitário e professor contratado III da Escola de Comunicações e Artes da Universidade de São Paulo (USP). Doutor em ciências da comunicação pela Universidade de São Paulo (USP). E-mail: rafael-ng@uol.com.br

Resumo: A disciplina "metodologia de pesquisa", tal como ensinada nas graduações de comunicação, pode ser vista como um microcosmos das questões epistemológicas da área. Este artigo analisa os programas de ensino de trinta universidades para delinear algo do que se pensa sobre esse nome nos cursos de comunicação com habilitação em jornalismo. A análise indica três elementos: (a) há uma preocupação maior com questões sobre conhecimento e ciência do que com comunicação; (b) escrita e formatação superam problemáticas epistemológicas; assim como (c) as particularidades da pesquisa em comunicação quase não são endereçadas.

Palavras-chave: metodologia; epistemologia; teoria da comunicação; ensino.
Abstract: The "research methods" discipline, as taught in undergraduate communication courses, can be seen as a microcosmos of the ongoing epistemological debates in the area. This paper analyses syllabi gathered from 30 Brazilian universities to outline what is thought about this name in communication programs with major in journalism. The analysis indicate three elements: (a) the concern about questions on knowledge and science surpass those on communication; (b) epistemology is shadowed by writing and formatting technique; (c) the particularities of communication research are not often addressed.

Keywords: method; epistemology; communication theory; teaching. 
1. GUTERRES, A. Bolsista de iniciação científica: a ponte entre o cidadão e o pesquisador. MALDONADO, A. E. et al. Metodologias de pesquisa em comunicação: olhares, trilhas e processos. Porto Alegre: Sulina, 2006, p. 256.

2. RANCER, A. S.; DURBIN, J. M.; LIN, Y. Teaching communication research methods: student perceptions of topic difficulty, topic understanding, and their relationship with math anxiety. Communication Research Reports, London, v. 30, n. 3, July/Sept. 2013, p. 246.

3. BAPTISTA, M. L. C. Disciplinas teóricas: de entuIho de currículo a campo do desejo e autopoiese. Trabalho apresentado no XXVI Intercom. Belo Horizonte/MG, 2 a 6 de setembro de 2003. Disponível em: <http://www. intercom.org.br/papers/ nacionais/2003/www/ pdf/2003_NP01_baptista.pdf $>$. Acesso em: 5 out. 2017.

4. BONIN, J. A. A dimensão metodológica na pesquisa comunicacional e os desafios da observação em perspectiva histórica. MALDONADO, A. E.; BONIN, J. A.; ROSÁRIO, N. M. (orgs.). Perspectivas metodológicas em comunicação: novos desafios na prática investigativa. João Pessoa: Editora da UFPB, 2008. p. 35.

5. MARTINO, L. M. S. Descontinuidades epistemológicas na teoria da comunicação: um estudo das taxonomias entre 1969 e 2011. Logos, Rio de Janeiro, v. 22, n. 1, p. 105-120, 2015 Disponivel em: <http:// www.e-publicacoes.uerj. br/index.php/logos/article/view/19557/14201>

Acesso em: 8 out. 2017.

\section{INTRODUÇÃO}

Se podemos começar este texto mencionando uma inquietação difusa, observada nas entrelinhas de conversas nos corredores acadêmicos, diremos que a disciplina "metodologia de pesquisa" geralmente não é situada entre as mais prestigiosas ou conceituadas. Vista muitas vezes por alunas e alunos como a matéria em que se aprende a "formatar textos", as expectativas em relação ao conteúdo tendem a ser relativamente baixas, em um certo "preconceito" com a pesquisa, como identifica Guterres ${ }^{1}$.

Além disso, nos cursos focados mais na formação técnico-profissional do que na reflexão crítica sobre as práticas, a disciplina de metodologia às vezes é questionada em termos de sua "aplicação", voltada, nesses termos, apenas para a elaboração dos trabalhos de conclusão de curso. No contexto anglo-saxônico, Rancer, Durbin e Lin $^{2}$, por exemplo, identificam a percepção dessa matéria como "difícil” não só para alunas e alunos, mas também para os docentes.

Evidentemente, começar com essa perspectiva no limite do anedótico - ou do trágico, conforme se observa a questão - não impede que sejam realizados excelentes trabalhos didático-pedagógicos, nos quais a construção de conhecimento, na relação docentes-discentes, acontece de maneira dialógica para uma compreensão crítica da realidade.

É nesse sentido, recuperando uma posição de Baptista ${ }^{3}$, que a disciplina fica entre o "entulho de currículo" e a oportunidade de se tornar um "campo de desejo e autopoiese". Ou, como recorda Bonin ${ }^{4}$, "a dimensão metodológica não pode ser tomada como menor, como simples operação técnica cuja garantia de validade se daria pela aplicação canônica de preceitos edificados em catecismos metodológicos seguidos à risca”.

Finalmente, assinale-se como lugar de fala que os autores deste artigo, docentes dessa disciplina, participam dos questionamentos elaborados aqui - a dimensão é, sobretudo, do diálogo e da pergunta, não da norma e do dever.

É nessa perspectiva que, a partir das práticas de sala de aula, questionamentos sobre a disciplina não apenas emergem, mas também começam a tomar forma no delineamento de questões de pesquisa: o que se entente, nos cursos de comunicação, por "metodologia de pesquisa"? Qual o espaço, nas matrizes curriculares, para trabalhar a pesquisa em comunicação?

O debate, do ponto de vista deste texto, ultrapassa consideravelmente o âmbito didático-pedagógico, podendo ser enfeixado no espaço de questões epistemológicas mais amplas.

Disciplina presente em inúmeros cursos de graduação, o discurso que se forma em torno da noção de "metodologia de pesquisa" é um indicativo, quase um microcosmos, de algumas indefinições epistemológicas presentes na área, assim como acontece no caso de teoria da comunicação ${ }^{5}$.

Parte dos problemas epistemológicos da comunicação está ligada, de um modo ou de outro, a questões metodológicas. Os debates em torno do objeto, 
de um olhar para definir comunicação ${ }^{6}$, da pertinência de determinados temas ${ }^{7}$ ou de procedimentos vinculados ao avanço das pesquisas na área se referem, em boa medida, a problemas metodológicos.

Todo o processo de pesquisa, como lembra Lopes ${ }^{8}$, é um processo metodológico. Não há como conceber a pesquisa em comunicação sem um olhar metodológico. No entanto, o rigor no método não significa rigidez na pesquisa, no sentido de engessamento, recordam Bourdieu; Passeron; Chamboredon ${ }^{9}$.

Como afirma Tamires Coelho ${ }^{10}$, "o conhecimento pode ser produzido com seriedade e rigor acadêmico, mas simultaneamente com flexibilidade e criatividade, evidenciando as marcas do pesquisador durante o processo de pesquisa".

De que maneira essas questões estão articuladas com o cotidiano das pesquisas na graduação, em suas ligações com programas de pós-graduação ${ }^{11}$ ? Como, tanto na iniciação científica quanto na elaboração de monografias finais de curso, se formam as próximas gerações de pesquisadoras e pesquisadores?

Não que falte bibliografia específica: os livros de Lopes $^{12}$, Santaella ${ }^{13}$, e Maldonado et al. ${ }^{14}$, assim como artigos de Braga ${ }^{15}$ mostram preocupação a respeito do tema. No entanto, é na prática de sala de aula, nesse aspecto, que se pode observar como as proposições epistemológicas em circulação na área se transformam em atividades de pesquisa.

Dessa forma, a sala de aula materializa "saberes instituídos" e é local privilegiado para observação dos lugares em disputa de um campo. O dispositivo analítico de entrada para a sala de aula é o currículo, que nos dá pistas sobre esse "terreno disputado", como nos mostra Oliveira ${ }^{16}$ em relação aos cursos de jornalismo. O programa ou plano de ensino das disciplinas de um curso, portanto, acaba por evidenciar os caminhos trilhados, o que se visibiliza preferencialmente e o que é invisibilizado. No que concerne à disciplina de metodologia, podemos compreender visões de pesquisa, método e comunicação, projetando consequências para a formação do profissional.

Este texto se alinha em quatro partes; três delas seguem o modelo dos programas de ensino (título, ementa e bibliografia), precedidas de uma breve discussão metodológica a respeito da definição do objeto desta pesquisa.

\section{ENTRE CURSO E HABILITAÇÕES: A COMUNICAÇÃO EM SUAS DERIVAÇÕES}

A obtenção dos programas de ensino da disciplina, procedimento metodológico que, a princípio, parecia relativamente simples - seria o caso apenas de encontrá-los na internet ou de solicitá-los às faculdades -, pareceu aos poucos revelar, em si, algumas problemáticas da área. A primeira delas, diretamente vinculada ao objeto, refere-se à definição de quais programas de metodologia de pesquisa seriam analisados. A busca inicial era por programas de cursos de comunicação.
6. SIGNATES, L. O que é especificamente comunicacional nos estudos brasileiros de comunicação na atualidade. In: BRAGA, J. L.; GOMES, P. G.; FERREIRA, J.; FAUSTO NETO, A. Dez perguntas para produção do conhecimento em comunicação. São Leopoldo: Unisinos, 2013. p. 153-179.

7. CARVALHO, C. A.; LAGE, L. Pela adoção da perspectiva da pertinência em pesquisas comunicacionais. Anais do XXI Encontro da Compós, Juiz de Fora, 12 a 15 de junho de 2012. Disponível em: <http:// www.compos.org.br/data/ biblioteca_1879.pdf $>$. Acesso em: 8 out. 2017.

8. LOPES, M. I. V. Pesquisa em comunicação. São Paulo: Loyola, 1999.

9. BOURDIEU, P.; CHAMBOREDON, J.-C. e PASSERON, J.-C. Ofício de sociólogo: metodologia da pesquisa na sociologia. Petrópolis, RJ: Vozes, 2004.

10. COÊLHO, T. F. Percursos metodológicos na construção de uma pesquisa sobre as relações comunicativas interculturais na comunidade $C S$ POA. In: BONIN, J. A.; ROSÁRIO, N. M. (orgs.). Processualidades metodológicas: configurações transformadoras em comunicação. Florianópolis: Insular, 2013, v. 1, p. 275.

11. WEBER, K.; MARTIN, M. M. Pedagogy in practice: linking the graduate research methods course with communication theory. Communication Research Reports, London, v. 23, n. 1, jan. 2006, p. 63-67. LACERDA, J. S. et al. A pesquisa da pesquisa em processos de IC e TCC para a formação de novos pesquisadores. In: MALDONADO, A. E. et al. (orgs.). Epistemologia, investigação e formação científica em comunicação. Rio do Sul: Unidavi; EdUFRN, 2012. p. 323-338. 
12. Idem.

13. SANTAELLA, L. Comunicação e pesquisa. São Paulo: Hacker, 2003.

14. MALDONADO, A. E. et al. Metodologias de pesquisa em comunicação: olhares, trilhas e processos. Porto Alegre: Sulina, 2006.

MALDONADO, A. E.; BONIN, J. A.; ROSÁRIO, N. M. (orgs.). Perspectivas metodológicas em comunicação: novos desafios na prática investigativa. João Pessoa: Editora da UFPB, 2008.

MALDONADO, A. E. et al. (orgs.). Epistemologia, investigação e formação científica em comunicação. Rio do Sul: Unidavi; EdUFRN, 2012.

15. BRAGA, J. L. Para começar um projeto de pesquisa. Comunicação \& Educação, São Paulo, v. 10 , n. 3, p. $288-296$ set./dez. 2005. Disponível em: <http://www.revistas. usp.br/comueduc/article/ view/37542/40256>. Acesso em: 5 out. 2017.

BRAGA, J. L. A prática da pesquisa em comunicação: abordagem metodológica como tomada de decisões. E-Compós, Brasília, v. 14, n. 1, jan./ abr. 2011. Disponível em: <http://compos.org. $\mathrm{br} / \mathrm{see}$ r/index.php/e-compos/article/viewFile/665/503>. Acesso em: 5 out. 2017.

16. OLIVEIRA, M. R. Sobre fronteiras no jornalismo: o ensino e a produção da identidade profissional. Tese de doutorado em Comunicação. Universidade Federal Fluminense, Rio de Janeiro, 2011.

17. É importante salientar que em setembro de 2013 foram aprovadas as diretrizes curriculares nacionais para os cursos de relações públicas e jornalismo, os quais deixam de ser habilitações da comunicação social.
No entanto, logo começou a se delinear no horizonte um problema a respeito do que é um "curso de comunicação": no universo da graduação, a divisão por habilitações profissionais pareceu ser imperativa, na maior parte dos casos, para a definição dos programas ${ }^{17}$.

A rigor, exceto nominalmente, parecem não existir cursos de "comunicação", mas habilitações profissionais que se referem, cada qual à sua maneira, a uma área de comunicação com algumas afinidades eletivas de pouca sustentação epistemológica comum ${ }^{18}$. Assim, programas de "metodologia de pesquisa", embora muitas vezes denominados "metodologia de pesquisa em comunicação", estavam localizados no interior dos projetos pedagógicos dos cursos, entendendo-se, aqui, "cursos" como "habilitações", e não como uma eventual área de "comunicação".

Essa percepção, feita no começo da pesquisa, exigiu uma alteração no foco, uma vez que há dificuldade de encontrar, em termos formais - e levamos em conta a vinculação declarada de cada programa de ensino - uma ligação com a "comunicação".

Por conta disso, a procura por "metodologia de pesquisa" em "comunicação" foi praticamente inviável, na medida em que aparecia muito mais como uma disciplina vinculada às habilitações do que propriamente um corpo geral de conhecimentos voltado para a formação da pesquisa "em comunicação". Optou-se, a partir daí, por trabalhar a ideia de buscar programas da disciplina "metodologia" nos cursos de jornalismo, o mais antigo da área de comunicação - o primeiro curso data de 1947.

Esses problemas metodológicos sugerem algumas questões sobre a área. Trata-se, ao que parece, de uma assimetria entre a proposta de fundamentação epistemológica da área, de um lado, entendida como "comunicação", e, de outro, a demanda pela formação profissional, refletida sobretudo na composição das habilitações específicas.

A partir dessa mudança de "comunicação" para "jornalismo", ficou relativamente fácil encontrar programas de ensino. Isso reforça a percepção de um paradoxo assinalado alhures: embora os cursos sejam denominados de "comunicação", os direcionamentos reforçam a divisão entre habilitações "jornalismo", "publicidade e propaganda", "relações públicas", "rádio e TV" e assim por diante. Se, academicamente, a ênfase é na comunicação como área, a organização dos cursos se pauta em outra lógica, que destaca o elemento profissional em relação ao propriamente comunicacional.

A aluna ou aluno não ingressa nesses cursos para ter uma formação nos estudos de comunicação, mas sobretudo para conseguir uma habilitação profissional, ligada às demandas de um mercado organizado em torno de empresas que demandam exatamente as especificidades de uma formação de "técnicos de um saber prático", como denomina Sartre ${ }^{19}$, para além de uma compreensão da totalidade dos processos.

Nesse sentido, não surpreende que a busca por "metodologia de pesquisa em comunicação" tenha resultado em um número pequeno de programas de 
ensino, questão resolvida quando se substitui "comunicação" por "jornalismo", com um considerável aumento de resultados. Foi possível, dessa maneira, constituir um corpus de pesquisa como objeto de sondagem pautado apenas nos resultados relacionados ao jornalismo, não à comunicação.

A escolha por trabalhar a disciplina "metodologia de pesquisa" no âmbito dos cursos de jornalismo decorre de uma percepção que, reduzida ao absurdo, permitiria afirmar que não foram escolhidos programas de "metodologia de pesquisa em comunicação" porque eles não existem.

Conseguimos localizar 33 programas de ensino das seguintes instituições: Facha, Fapepe, FAT, Mackenzie, PUC-GO, PUC-RJ, UCB, UEL, Uemg, Ufal, UFG, Ufma, Ufop, UFPE, Ufpel, UFPR, UFRN, UFRRJ, Ufsc, UFSJ, UFTO, UFU, Ulbra, Unesp, Unifieo, Unifin, Unifra, UniPampa, UniPotiguar e UniSant'anna ${ }^{20}$. A pesquisa, de caráter exploratório, foi realizada no mês de maio de 2016, e analisamos todos os programas que conseguimos localizar, o que, certamente, deixa muitas universidades de fora do corpus. Note-se que a maioria dos programas de ensino localizados são pertencentes a universidades públicas. Contudo, a nosso ver, isso não inviabiliza a pesquisa, pois o intuito é mais de explorar o tema do que de fazer um censo ou um survey.

\section{A DEFINIÇÃO DO NOME DA DISCIPLINA}

Talvez um primeiro problema a abordar seja em relação ao nome da disciplina. Nota-se considerável variedade de títulos: vinte nomes diferentes encontrados em 33 programas de ensino. Essa pluralidade é particularmente interessante na medida em que os títulos apontam para perspectivas diferentes em relação à expectativa de conteúdo que formam ao redor dessa disciplina.

Evidentemente vale lembrar que o título de uma disciplina nem sempre é um indicador de seu conteúdo, sendo formulado, por vezes, na esteira de demandas burocráticas, institucionais ou mesmo a partir da trajetória de docentes associados à disciplina em determinado momento. Por outro lado, o título constitui a identidade fundamental de delimitação epistemológica de uma disciplina, sua abrangência e escopo: ao intitular uma matéria desta ou daquela maneira, faz-se também uma opção dentro das políticas em circulação no campo acadêmico, aproximando-a de determinados conteúdos e práticas ao mesmo tempo que a distancia de outros.

Nesse sentido, a pluralidade de títulos de "metodologia" pode ser tomada como um indicativo de certa falta de consenso a respeito do que significa pensar essa matéria, a começar pela natureza do que se está investigando.

Encontramos vinte nomes diferentes para as disciplinas. O termo "comunicação", como delimitador do que se ensina, aparece em cinco das vinte denominações encontradas (como podemos observar no Quadro 1). Os outros títulos não fazem referência à "comunicação", preferindo "pesquisa" ou "trabalho científico" de maneira geral.
18. O que, de alguma maneira, se aprofunda com as novas diretrizes curriculares nacionais relacionadas ao curso de jornalismo, por exemplo. 19. SARTRE, J.-P. Em defesa dos intelectuais. São Paulo: Ática, 1997, p. 26.

20. Algumas instituições possuíam mais de uma disciplina relacionada à metodologia: são 33 programas de trinta instituições de ensino. 


\section{Quadro 1: Diversidade de nomenclaturas referente à disciplina}

\begin{tabular}{l|l} 
INCIDENCIA & \multicolumn{1}{|c}{ NOME ATRIBUÍDO À DISCIPLINA } \\
\hline 6 & Metodologia da pesquisa em comunicação \\
\hline 3 & Teoria(s) e método(s) da pesquisa em comunicação \\
\hline 3 & Metodologia do trabalho científico \\
\hline 2 & Metodologia científica \\
\hline 2 & Pesquisa aplicada à comunicação \\
\hline 2 & Pétodos e técnicas da pesquisa em comunicação \\
\hline 2 & Metodologia da pesquisa \\
\hline 1 & Introdução à pesquisa bibliográfica e à documentação \\
\hline 1 & Epistemologias da comunicação (disciplina optativa) \\
\hline 1 & Metodologia de pesquisa \\
\hline 1 & Métodos e técnicas de pesquisa \\
\hline 1 & Pesquisa em jornalismo \\
\hline 1 & Fundamentos de técnicas e métodos científicos \\
\hline 1 & Metodologia da ciência \\
\hline 1 & Práticas investigativas \\
\hline 1 & Iniciação ao trabalho acadêmico \\
\hline 1 & Introdução ao pensamento científico \\
\hline 1 & Metodologia e técnicas de pesquisa em jornalismo \\
\hline 1 & Metodologia do estudo e da pesquisa I e II \\
\hline 1 & \\
\hline 1 & Pesano \\
\hline 1 & \\
\hline 1 &
\end{tabular}

Fonte: Elaborado pelos autores.

Vale notar, como será explorado posteriormente, que a indicação de "comunicação" não se reflete, necessariamente, em algum direcionamento do conteúdo: esse elemento específico no título não significa algo semelhante nas ementas e bibliografias.

No entanto, pode-se observar a presença dessa palavra no título como um indicador de certa delimitação no que se refere - ou poderia se referir - a uma abordagem epistemológica particular. Não seria demais encontrar aí, também, certa preocupação em demarcar o que há de específico na pesquisa "em comunicação", vista como algo diferente do que seria o conjunto de investigações de outras áreas - o que atua também como baliza político-institucional.

O segundo fator que chama atenção a respeito do nome é a presença dos adjetivos "científica", "científico" ou de termos próximos a "ciência". Nove dos 33 programas utilizam expressões como essas no título da disciplina, oscilando desde "introdução ao pensamento científico", com uma ocorrência, até "metodologia científica" ou "metodologia do trabalho científico". Esses termos deixam de lado a questão específica da comunicação para abrir um leque mais amplo de expressão. 
Ao mesmo tempo, a presença da ideia de "ciência" e "científico" em um curso de comunicação não deixa de indicar, ao menos em parte, a possibilidade de uma investigação propriamente "científica" da área. O título da disciplina, nesse caso, parece vir carregado de um sentido que indica a presença do "científico" nos estudos de comunicação. Nota-se certa ênfase na noção de "trabalho científico" em comunicação, ao passo que debates da área têm questionado, ao longo das duas últimas décadas, a possibilidade de fazer pesquisa "científica" em comunicação - ao menos em relação a uma concepção de ciência.

Isso nos leva a outra questão: em que medida é possível falar, de fato, em pesquisa "científica" na área? Ross ${ }^{21}$ recorda que, embora com a ideia de "fazer pesquisa”, estudantes raramente são desafiados a pensar o que é, de fato, pesquisar. Mais ainda: de qual concepção de ciência se está falando?

Vale recordar uma observação de Gewandsznajder ${ }^{22}$ a respeito da possibilidade de falar em "ciências" no âmbito das chamadas "ciências sociais". Na perspectiva do autor, a noção de "ciência social" decorre muito das demandas de legitimidade das investigações sociais diante das ciências ditas "exatas". Seguindo esse pensamento, falar em "ciência da comunicação" na atualidade requer uma noção de ciência diferente da positivista; uma ciência, retomando a perspectiva de Dilthey ${ }^{23}$, muito mais próxima da compreensão do que propriamente da explicação.

Há certo descompasso entre os programas que delimitam a pesquisa "em comunicação" e os que optam por falar em pesquisa "científica".

Em dois programas de ensino a opção é por associar a pesquisa não à "comunicação", mas ao "jornalismo". Isso parece uma tentativa de delimitar o foco: se a pesquisa é em "comunicação", um objeto como histórias em quadrinhos ou telenovela pode ser acolhido a partir de vários olhares, algo que talvez não aconteça se a pesquisa for em "jornalismo" - lembrando que a construção da pesquisa não se dá a partir do objeto, mas da formação de um olhar sobre $\mathrm{ele}^{24}$.

Nesse sentido, a delimitação da disciplina pelo jornalismo talvez não resolva os problemas epistemológicos da pesquisa em comunicação, na medida em que estabelecer um "olhar a partir do jornalismo" para um trabalho acadêmico não parece ser muito mais simples do que identificar um "viés comunicacional" a partir do qual se poderia estudar.

Dois programas, nesse sentido, mencionam a pesquisa "aplicada" à comunicação. A noção de "aplicação", no entanto, não parece se resumir ao emprego de determinadas práticas na investigação de um fenômeno, mas, a julgar pelas ementas, compreende certo direcionamento ao fator "prático" da pesquisa.

A presença da palavra "técnica" em cinco dos programas sugere, do mesmo modo, certo caráter "instrumental" na pesquisa em graduação. Essa parte instrumental da disciplina é geralmente a mais recordada nas conversas de corredor. O título "métodos e técnicas" ou "metodologia e técnicas" parece indicar a perspectiva de "aplicação", no sentido de uma "produção" para a qual podem ser dirigidos os esforços da disciplina.
21. ROSS, D. G. Defining "research": undergraduate perceptions of research in a technical communication classroom. Journal of Technical Writing and Communication, Fitchburg, MA, v. 44, n. 1, 61-99, 2014.

22. GEWANDSZNAJDER, F. As ciências sociais são ciências? In: ALVES-MAZZOTTI, A. J.; GEWANDSZNAJDER, F. (orgs.). $O$ método nas ciências naturais e sociais: pesquisa quantitativa e qualitativa. São Paulo: Pioneira, 2002. p. 111-128.

23. DILTHEY, W. Introdução às ciências humanas. Rio de Janeiro: Gen, 2010.

24. SODRÉ, M. Ensinar e pesquisar. In: MOREIRA, S. V. e VIEIRA, J. P. D. (orgs.). Comunicação: ensino e pesquisa. Rio de Janeiro: EdUERJ, 2008. p. 71-90. 
No polo oposto, três programas trabalham com a palavra "teoria(s) e método(s) da pesquisa" no título, ampliando o foco de modo a apontar não apenas para a produção de uma investigação, mas também, ao que tudo indica, para a reflexão teórica a respeito do fazer científico - hipótese confirmada pelas ementas. Não se trata, vale observar, da junção de uma disciplina metodológica e "teoria(s) da comunicação", mas da acentuação do elemento de debate propriamente "metodológico" - em contraposição a "método" - possível. Isto é, a pesquisa tem elementos teóricos e metodológicos.

Existem três disciplinas "afins", em universidades diferentes. Embora apenas uma delas tenham título próximo de "metodologia" ou "métodos", todas parecem estar relacionadas a esse campo de atuação. A disciplina "metodologia de estudo e da pesquisa" coloca no título a questão da prática universitária, como uma espécie de orientação nesse sentido. "Introdução ao pensamento científico" sugere uma etapa anterior de familiarização com o tema - e, vale notar, a mesma universidade oferece também a disciplina de "metodologia". Finalmente, em uma universidade, existe uma disciplina optativa intitulada "epistemologias da comunicação”, único caso de aproximação, ao menos em nível de graduação, entre questões propriamente teóricas e metodológicas.

As indicações dos títulos, como sugerido, não podem ser tomadas como sinal inequívoco dos conteúdos, mas insinuam sobretudo a delimitação de espaços. O elemento seguinte, talvez mais revelador de determinadas questões epistemológicas, refere-se ao ementário das disciplinas.

\section{CONSENSO E DISPERSÃO: OS ENFOQUES DAS EMENTAS}

À primeira vista, as ementas dos programas de ensino sugerem um panorama relativamente homogêneo em termos de definição do que significa a disciplina "metodologia". Como indica Lopes ${ }^{25}$, as ementas devem "estar ancoradas firmemente naquilo que constitui o conhecimento gerado pela investigação da comunicação”.

Os pontos específicos da disciplina parecem estar delimitados: em apenas uma das ementas há referência direta a outra matéria, "teorias da comunicação"; e, em outra, nota-se ênfase na pesquisa sobre opinião pública.

Todos os programas analisados mencionam algum tipo de discussão a

25. LOPES, M. I. V. A pesquisa e o ensino nas escolas de comunicação. In: PERUZZO, C. M. K.; SILVA, R. B. Retrato do ensino em comunicação no Brasil. São Paulo: Intercom; Taubaté: Unitau, 2003. p. 288. respeito do que é ciência, e, ao mesmo tempo, são voltados quase que em sua totalidade para a elaboração de um projeto de pesquisa - o que significa, em nove dos programas analisados, menções diretas à normatização e/ou formatação, estando esse tópico sugerido nos demais.

Essa presença constante da questão formal pode ser compreendida, entre outros elementos, pelo fato de se tratar de programas de ensino de graduação, o que permite supor um contato inicial com o tema. 
O segundo tópico presente em quase todas as ementas, exceto em uma, é a discussão a respeito da teoria do conhecimento, trabalhada com mais ou menos ênfase conforme o programa. As modalidades de abordagem da realidade, associadas ou não com a discussão sobre o pensamento científico, são recorrentes nas ementas, sugerindo uma vez mais a existência de elementos adicionais, para além do propriamente "formal", na disciplina.

Assim como nos títulos, se enfatizam as palavras "ciência" e "científico" nas ementas. A discussão sobre essas noções está presente em vários programas analisados. O "científico" aparece como uma postura vinculada às discussões sobre metodologia - embora, vale observar, a "cientificidade" da comunicação como objeto ou área não esteja presente em nenhuma das ementas.

Isso leva a um problema subjacente a ser explorado.

À primeira vista, parece existir uma surpreendente unidade dos programas de metodologia. Por que surpreendente? Porque quando se compara essa convergência de ideias em metodologia com a dispersão constatada na área sobre teoria e epistemologia da comunicação, como indicado em outros momentos ${ }^{26}$, é interessante observar um direcionamento na parte de métodos.

Talvez o delineamento de uma resposta passe pela pergunta sobre qual consenso existe nos programas de metodologia.

A observação das ementas mostra, em dezessete dos trinta programas analisados, a ausência da palavra "comunicação" ou de outra indicação que permita identificar um elo com a área.

As discussões propostas referem-se a questões epistemológicas gerais, sem vínculos diretos com problemas da comunicação. Esse debate, a julgar pelas ementas, é atravessado por definições de ciência, modos de conhecimento, procedimentos técnicos e redação acadêmica.

Mesmo quando os programas de ensino mencionam diretamente a palavra “comunicação”, o cenário não é diferente. A indicação não significa a presença de elementos que permitam situar ou problematizar as questões da comunicação. Não há, nas ementas, temas, objetos e métodos específicos da comunicação. Os questionamentos epistemológicos, como a definição de objetos, olhares e perguntas, parecem ausentes dos programas. O exame das ementas sugere uma preocupação com a instrumentalidade de pesquisas, independentemente das discussões a respeito de práticas metodológicas.

Evidentemente não estamos sugerindo que isso seja, por si, algo bom ou ruim. "O desafio metodológico", indica Marin²7, "está em pensar a produção do conhecimento como processo de criação, que se estabelece no constante fluxo e refluxo entre o teórico e o empírico".

No entanto, essa ausência pode ser relacionada de modo significativo com um problema recorrente da área: definir o que é pesquisa "em comunicação".

Parece existir uma percepção tácita do que se vai estudar ao falar de "comunicação”, mas isso não é indicado senão de modo tangencial: alguns programas evidenciam o jornalismo, mas não há, por exemplo, menções à mídia. Aliás,
26. FRANÇA, V. R. V. Paradigmas da comunicação: conhecer o quê? In: MOTTA, L. G. et al. (orgs.) Estratégias e culturas da comunicação. Brasília: Editora UnB, 2001. p. 13-29.

27. MARIN, E. C. O ofício da pesquisa: processos do fazer. In: MALDONADO, A. E. et al. Metodologias de pesquisa em comunicação: olhares, trilhas e processos. Porto Alegre: Sulina, 2006. p. 66. 
28. ALBUQUERQUE, A. Os desafios epistemológicos da comunicação mediada por computador. Revista Fronteiras Porto Alegre, v. 4, n. 2 , dez. 2002

FELINTO, E. Da teoria da comunicação às teorias da mídia: ou, temperando a epistemologia com uma dose de cibercultura. Anais do XX Encontro da Compós. Porto Alegre, junho de 2011. Disponível em: <http://www.compos.org.br/data/biblioteca_1579.pdf>. Acesso em: 5 out. 2017.

MARTINO, L. C. Interdisciplinaridade e objeto de estudos da comunicação. In: FAUSTO NETO, A. et al. (orgs.). O campo da comunicação: categorização, problematizações e perspectivas. João Pessoa: Editora da UFPB, 2001. p. $52-74$. destaque-se que essa palavra, elemento central em algumas discussões sobre pesquisa em comunicação ${ }^{28}$, não aparece em nenhuma das ementas analisadas.

Nesse sentido, paradoxalmente, o consenso parece se transformar em dispersão: a ausência de abordagens sobre a construção de objetos de pesquisa em comunicação, assim como a falta de menções a problemas de definição dos olhares comunicacionais mostram que, para além da superfície do consenso, se delineia uma percepção difusa a respeito do que é, propriamente, uma pesquisa "em comunicação".

É agora que as razões do consenso sugerido parecem começar a se explicitar. De modo bastante geral, seria possível avançar uma hipótese, quase um questionamento: o consenso existente se deve ao fato de os programas de metodologia em comunicação não discutirem comunicação. As ênfases são mais em "projetos de pesquisa", "técnicas de pesquisa", ou nas normas da ABNT. Com isso, perdem-se de vista o olhar comunicacional e a metodologia como processo, deixando de lado questões epistemológicas da comunicação. Além do mais, tampouco se discute a relação desses projetos e técnicas de pesquisa com a questão profissional dos cursos, no caso, do jornalismo.

\section{A CIÊNCIA: O GERAL E O ESPECÍFICO NAS BIBLIOGRAFIAS}

A bibliografia mencionada nos programas de ensino é também um indicador do que se entende por "metodologia", "métodos" e, de maneira geral, pesquisa em comunicação. Há um pequeno número de obras recorrentes na maior parte dos programas - nenhuma é citada em todos eles -, secundado por uma maioria de livros menos citados.

A presença de um título na bibliografia, claro, não é garantia de uso da obra em sala de aula, e menos ainda da qualidade desse uso.

No entanto, se as disciplinas universitárias são um discurso de saber sobre a realidade, a bibliografia é um ponto visível dessa produção. Os discursos teóricos, aliás, se caracterizam justamente por fazer referências constantes a suas origens, daí a bibliografia ser um dos itens observados neste estudo.

São mencionados, no total, 160 títulos nos programas de ensino. Em geral, a divisão é entre "básica", bibliografias com três indicações, e "complementar", com cinco - havendo duas exceções. Cinco programas não mencionavam a bibliografia ou o conteúdo programático, constando apenas a ementa. Há predomínio considerável da escolha por livros em relação a artigos científicos: nove artigos contra 153 livros.

É possível observar, na bibliografia, um reflexo dos elementos assinalados em outros itens: a questão das "normas de formatação" se sobrepõe à discussão metodológica, e o debate geral sobre ciência ganha das reflexões sobre comunicação. Isso pode ser observado, de saída, a partir de algumas indicações numéricas - sem nenhum tipo de fim "representativo" ou "amostral", mas apenas indicativo. 


\section{Quadro 2: Títulos mais mencionados nos programas}

\begin{tabular}{l|c|l}
\multicolumn{1}{c|}{ NOME DO LIVRO } & MENÇÕES & \multicolumn{1}{c}{ FOCO } \\
$\begin{array}{l}\text { LAKATOS, Eva; MARCONI, Marina. Metodologia do } \\
\text { trabalho científico. São Paulo: Atlas, 2007. }\end{array}$ & 20 & $\begin{array}{l}\text { Reflexão científica } \\
\text { geral }\end{array}$ \\
\hline $\begin{array}{l}\text { BARROS, Antônio; DUARTE, Jorge. (orgs.). Metodologias } \\
\text { e técnicas de pesquisa em comunicação. São Paulo: } \\
\text { Atlas, 2006. }\end{array}$ & 13 & $\begin{array}{l}\text { Reflexão científica } \\
\text { geral }\end{array}$ \\
\hline $\begin{array}{l}\text { GIL, Antônio Carlos. Como elaborar projetos de } \\
\text { pesquisa. São Paulo: Atlas, 1996. }\end{array}$ & 12 & $\begin{array}{l}\text { Reflexão científica } \\
\text { geral }\end{array}$ \\
\hline $\begin{array}{l}\text { LOPES, Maria Immacolata Vassallo. Pesquisa em } \\
\text { comunicação. São Paulo: Loyola, 1997. }\end{array}$ & 11 & $\begin{array}{l}\text { Pesquisa em } \\
\text { comunicação }\end{array}$ \\
\hline $\begin{array}{l}\text { LAGO, Cláudia. Metodologias de pesquisa em } \\
\text { jornalismo. Petrópolis, RJ: Vozes, 2008. }\end{array}$ & 10 & $\begin{array}{l}\text { Pesquisa em } \\
\text { jornalismo }\end{array}$ \\
\hline
\end{tabular}

Fonte: Produção das autoras.

Nenhum livro alcança a totalidade dos programas. O mais citado, Metodologia do trabalho científico, de Eva Lakatos e Marina Marconi, tem vinte menções. Na sequência, Metodologias e técnicas de pesquisa em comunicação, de Antônio Barros e Jorge Duarte, com treze citações; Como elaborar projetos de pesquisa, de Antonio Carlos Gil, com doze. Pesquisa em comunicação, de Maria Immacolata V. Lopes, é mencionado em onze bibliografias.

Não é de surpreender que os três livros mais citados sejam trabalhos que abordam a pesquisa de maneira geral, propondo uma reflexão sobre práticas científicas em seus aspectos mais amplos.

A opção dos programas é marcada pela preocupação em trabalhar elementos gerais da ciência e, em particular, da elaboração de projetos de pesquisa dentro de uma base normatizadora vinculada às questões de formato. Há menção direta às "normas da ABNT": a Norma 6023: informação e documentação, referências, elaboração aparece em três programas; enquanto a Norma 10520: Informação e documentação, apresentação de citações em documentos e a Norma 14724: Informação e documentação, trabalhos acadêmica-apresentação recebem duas citações cada.

Há quatro livros específicos sobre comunicação nas bibliografias: Pesquisa em Comunicação, de Lopes $^{29}$; Comunicação e Pesquisa, de Lúcia Santaella ${ }^{30}$, utilizado em seis universidades; Pesquisa empirica em comunicação, de Braga, Lopes e Martino ${ }^{31}$, em três; e Metodologias de pesquisa em comunicação: olhares, trilhas e processos, de Efendy Maldonado ${ }^{32}$, em duas.

\section{Quadro 3: Distribuição temática das obras}

\begin{tabular}{c|c}
\hline Reflexão científica geral & 74 \\
\hline Comunicação/teoria & 41 \\
\hline Pesquisa em comunicação & 24 \\
\hline Formatação e escrita & 21 \\
\hline & Fonte: Produção das autoras.
\end{tabular}

29. LOPES, M. I. V. Pesquisa em comunicação. São Paulo: Loyola, 1999

30. Idem.

31. BRAGA, J. L.; LOPES, Maria I. V.; MARTINO, L. C. (orgs.). Pesquisa empírica em comunicação São Paulo: Paulus, 2010.

32. MALDONADO, A. E. et al. Metodologias de pesquisa em comunicação: olhares, trilhas e processos. Porto Alegre: Sulina, 2006. 
Dos 160 livros citados, 21 podem ser considerados livros-textos ou manuais referentes à elaboração da pesquisa e questões de formatação, abrindo maior ou menor espaço para reflexões sobre assuntos do pensamento científico. Dos 82 restantes, quarenta dificilmente poderiam ser associados de imediato às práticas de pesquisa acadêmica, aproximando-se mais daquilo que é entendido, de maneira geral, como teoria da comunicação - Adorno e Horkheimer, Baudrillard, Bourdieu e McLuhan estão entre os autores citados. Sem, evidentemente, questionar a relevância ou lugar desses pensadores nos estudos de comunicação, nota-se, por outro lado, a ausência de vínculos específicos com questões metodológicas, ao menos no sentido normatizador-reflexivo que se pode encontrar nos programas de ensino. Os títulos restantes, 41 livros, oferecem subsídios para pensar tanto os procedimentos científicos quanto questões da área de comunicação e suas problemáticas.

Observa-se, aí também, certa disparidade entre a recorrência de livros gerais sobre ciência e técnicas de elaboração de projetos e a presença menor de produções a respeito da pesquisa em comunicação e, em específico, da pesquisa em jornalismo. Machado ${ }^{33}$ diagnostica também a escassez de manuais para orientar pesquisas em jornalismo, principalmente no que se refere à graduação.

Falar de metodologia não é somente abordar ABNT, projeto de pesquisa ou ciência em geral, mas é preciso conceber a pesquisa como um processo, por si próprio, metodológico. A partir do que analisamos, vemos a importância de trazer para o cerne da discussão o próprio campo da comunicação, sem o qual a graduação e a pós-graduação na área ficarão apartadas. Restabelecer o vínculo da disciplina de metodologia com a pesquisa em comunicação é, pois, restaurar os vínculos entre graduação e pós-graduação.

33. MACHADO, E. Metodologias de pesquisa em jornalismo: uma revisão histórica e perspectivas para a produção de manuais de orientação. Brazilian Journalism Research, Brasília, v. 6, n. 1, p. 10-28, 2010. Disponível em: <https://bjr. sbpjor.org.br/bjr/article/ view/245/243>. Acesso em: 8 out. 2017.

\section{REFERÊNCIAS BIBLIOGRÁFICAS}

ALBUQUERQUE, Afonso. Os desafios epistemológicos da comunicação mediada por computador. Revista Fronteiras, Porto Alegre, v. 4, n. 2, dez. 2002.

BAPTISTA, Maria Luiza Cardinale. Disciplinas teóricas: de entulho de currículo a campo do desejo e autopoiese. Anais do XXVI Congresso Brasileiro de Ciências da Comunicação. Belo Horizonte/MG, 2 a 6 de setembro de 2003. Disponível em: <http://www.intercom.org.br/papers/nacionais/2003/ www/pdf/2003_NP01_baptista.pdf>. Acesso em: 5 out. 2017.

BONIN, Jiani Adriana. A dimensão metodológica na pesquisa comunicacional e os desafios da observação em perspectiva histórica. MALDONADO, Alberto Efendy; BONIN, Jiani Adriana; ROSÁRIO, Nísia Martins. (orgs.). Perspectivas metodológicas em comunicação. João Pessoa: Editora da UFPB, 2008.

BOURDIEU, Pierre; CHAMBOREDON, Jean-Claude; PASSERON, JeanClaude. Ofício de sociólogo: metodologia da pesquisa na sociologia. Petrópolis, RJ: Vozes, 2004. 
BRAGA, José Luiz. Para começar um projeto de pesquisa. Comunicação \& Educação, São Paulo, v. 10, n. 3, p. 288-296, set./dez. 2005. Disponível em: $<$ http://www.revistas.usp.br/comueduc/article/view/37542/40256>. Acesso em: 5 out. 2017.

A prática da pesquisa em comunicação: abordagem metodológica como tomada de decisões. E-Compós, Brasília, v. 14, n. 1, jan./abr. 2011. Disponível em: <http://compos.org.br/seer/index.php/e-compos/article/ viewFile/665/503>. Acesso em: 5 out. 2017.

BRAGA, José Luiz; LOPES, Maria Immacolata Vassallo; MARTINO, Luiz Cláudio. (orgs.). Pesquisa empírica em comunicação. São Paulo: Paulus, 2010.

CARVALHO, Carlos Alberto; LAGE, Leandro. Pela adoção da perspectiva da pertinência em pesquisas comunicacionais. Anais do XXI Encontro Compós, Juiz de Fora, 12 a 15 de junho de 2012. Disponível em: <http://www.compos. org.br/data/biblioteca_1879.pdf>. Acesso em: 8 out. 2017.

COÊLHO, Tamires Ferreira. Percursos metodológicos na construção de uma pesquisa sobre as relações comunicativas interculturais na comunidade CS POA. In: BONIN, Jiani Adriana; ROSÁRIO, Nísia Martins. (orgs.). Processualidades metodológicas: configurações transformadoras em comunicação. Florianópolis: Insular, 2013, v. 1, p. 273-294.

DILTHEY, Wilhelm. Introdução às ciências humanas. Rio de Janeiro: Gen, 2010.

FELINTO, Erick. Da teoria da comunicação às teorias da mídia: ou, temperando a epistemologia com uma dose de cibercultura. Anais do XX Encontro da Compós, Porto Alegre, junho de 2011. Disponível em: <http:/ / www.compos.org.br/data/biblioteca_1579.pdf>. Acesso em: 5 out. 2017.

FRANÇA, Vera Regina Veiga. Paradigmas da comunicação: conhecer o quê? In: MOTTA, Luiz Gonzaga et al. (orgs.). Estratégias e culturas da comunicação. Brasília: Editora UnB, 2001. p. 13-29.

GEWANDSZNAJDER, Fernando. As ciências sociais são ciências? In: ALVESMAZZOTTI, Alda Judith. (orgs.). O método nas ciências naturais e sociais: pesquisa quantitativa e qualitativa. São Paulo: Pioneira, 2002. p. 111-128.

GUTERRES, Aline. Bolsista de iniciação científica: a ponte entre o cidadão e o pesquisador. MALDONADO, Alberto Efendy et al. Metodologias de pesquisa em comunicação: olhares, trilhas e processos. Porto Alegre: Sulina, 2006. p. 253-270. Disponível em: <http:/ / www.processocom.org/wp-content/ uploads/2017/03/azul0001.pdf>. Acesso em: 8 out. 2017.

LACERDA, Juciano de Sousa et al. A pesquisa da pesquisa em processos de IC e TCC para a formação de novos pesquisadores. In: MALDONADO, A. E. et al. 
(orgs.). Epistemologia, investigação e formação científica em comunicação. Rio do Sul: Unidavi; EdUFRN, 2012. p. 323-338.

LOPES, Maria Immacolata Vassallo. A pesquisa e o ensino nas escolas de comunicação. In: PERUZZO, Cicília Maria Krohling; SILVA, Robson Bastos. (orgs.). Retrato do ensino em comunicação no Brasil. São Paulo: Intercom; Taubaté: Unitau, 2003. p. 273-296.

Pesquisa em comunicação. São Paulo: Loyola, 1999.

MACHADO, Elias. Metodologias de pesquisa em jornalismo: uma revisão histórica e perspectivas para a produção de manuais de orientação. Brazilian Journalism Research, Brasília, v. 6, n. 1, p. 10-28, 2010. Disponível em: $<$ https://bjr.sbpjor.org.br/bjr/article/view/245/243>. Acesso em: 8 out. 2017.

MALDONADO, Alberto Efendy et al. Metodologias de pesquisa em comunicação: olhares, trilhas e processos. Porto Alegre: Sulina, 2006.

MALDONADO, Alberto Efendy; BONIN, Jiani Adriana; ROSÁRIO, Nísia Martins. (orgs.). Perspectivas metodológicas em comunicação: novos desafios na prática investigativa. João Pessoa: Editora da UFPB, 2008.

MALDONADO, Alberto Efendy et al. (orgs.). Epistemologia, investigação e formação científica em comunicação. Rio do Sul: Unidavi; EdUFRN, 2012.

MARIN, Elizara Carolina. O ofício da pesquisa: processos do fazer. In: MALDONADO, Alberto Efendy et al. Metodologias de pesquisa em comunicação: olhares, trilhas e processos. Porto Alegre: Sulina, 2006. p. 6592.

MARTINO, Luiz Cláudio. Interdisciplinaridade e objeto de estudos da comunicação. In: FAUSTO NETO, Antônio et al. (orgs.). O campo da comunicação. João Pessoa: Editora da UFPB, 2001. p. 52-74.

MARTINO, Luís Mauro Sá. Descontinuidades epistemológicas na teoria da comunicação: um estudo das taxonomias entre 1969 e 2011. Logos, Rio de Janeiro, v. 22, n. 1, p. 105-120, 2015. Disponível em: <http:/ /www.epublicacoes.uerj.br/index.php/logos/article/view/19557/14201>. Acesso em: 8 out. 2017.

OLIVEIRA, Michelle Roxo. Sobre fronteiras no jornalismo: o ensino e a produção da identidade profissional. Niterói, Tese de doutorado em Comunicação. Universidade Federal Fluminense, Rio de Janeiro, 2011.

RANCER, Andrew S.; DURBIN, James M.; LIN, Yang. Teaching communication research methods: student perceptions of topic difficulty, topic understanding, and their relationship with math anxiety. Communication Research Reports, London, v. 30, n. 3, July/Sept. 2013. 
ROSS, Derek G. Defining "research": undergraduate perceptions of research in a technical communication classroom. Journal of technical writing and communication, Fitchburg, MA, v. 44, n. 1, p. 61-99, 2014.

SANTAELLA, Lucia. Comunicação e pesquisa. São Paulo: Hacker, 2003.

SARTRE, Jean-Paul. Em defesa dos intelectuais. São Paulo: Ática, 1997.

SIGNATES, Luiz. O que é especificamente comunicacional nos estudos brasileiros de comunicação na atualidade. In: BRAGA, José Luiz; GOMES, Pedro Gilberto; FERREIRA, Jairo; FAUSTO NETO, Antônio. Dez perguntas para produção do conhecimento em comunicação. São Leopoldo: Unisinos, 2013. p. 153-179.

SODRÉ, Muniz. Ensinar e pesquisar. In: MOREIRA, Sônia Virgínia; VIEIRA, João Pedro Dias. (orgs.). Comunicação: ensino e pesquisa. Rio de Janeiro: EdUERJ, 2008. p. 71-90.

WEBER, Keith; MARTIN, Matthew M. Pedagogy in practice: linking the graduate research methods course with communication theory. Communication Research Reports, London, v. 23, n. 1, jan. 2006, p. 63-67. 